Pit

$$
\begin{aligned}
& \text { UEC 2 } 998 \text { GA-A22968 } \\
& \text { OSTI } \\
& \text { CONF-981126-- }
\end{aligned}
$$

\title{
OUTGASSING TESTS ON MATERIALS USED IN THE DIII-D MAGNETIC FUSION TOKAMAK
}

\author{
by
K.L. HOLTROP, M. HANSINK, and A.G. KELLMAN
}

DISTRIBUTION OF THS DOCUMENT IS UNGIMTIED ph

MASTER

DECEMBER 1998 


\section{DISCLAIMER}

Portions of this document may be illegible in electronic image products. Images are produced from the best available original document. 


\title{
OUTGASSING TESTS ON MATERIALS USED IN THE DIII-D MAGNETIC FUSION TOKAMAK
}

\author{
by \\ K.L. HOLTROP, M. HANSINK, and A.G. KELLMAN
}

This is a preprint of a paper to be presented at the 45th Annual American Vacuum Society Symposium and Topical Conference, November 2-6, 1998, Baltimore, Maryland and to be published in the Journal of Vacuum Science and Technology.

\author{
Work supported by \\ the U.S. Department of Energy \\ under Contract No. DE-AC03-89ER51114
}




\section{ABSTRACT}

In order to achieve high performance plasma discharges in the DIII-D magnetic fusion tokamak, impurity levels must be carefully controlled. Since first wall materials can desorb volatile impurities during these discharges, it is important to characterize and control the outgassing of these materials. An outgassing chamber was built to measure the outgassing properties of various materials used in the DIII-D vessel. The results of pump-down tests performed on ATJ graphite, thin Grafoil® gaskets, and $\mathrm{MgO}$ coaxial cables will be presented. In addition to pumpdown tests it was desired to study the behavior of the materials at temperatures up to $400^{\circ} \mathrm{C}$, which is the maximum temperature to which the DIII-D vessel is baked. The station was modified to include independent heating control of the sample and a simple load-lock chamber. 


\section{INTRODUCTION}

The DIII-D tokamak is used for plasma fusion research. In order to achieve high performance discharges impurities must be carefully controlled. For high $\mathrm{Z}(\mathrm{Z} \geq 20)$ materials, impurity fractions as low as $10^{-3}$ can have a considerable negative effect on the plasma although higher fractions of low $\mathrm{Z}$ impurities, e.g. carbon, can be tolerated. Since the typical density of a plasma is on the order of $5 \times 10^{19} \mathrm{~m}^{-3}$ and the plasma volume is approximately $20 \mathrm{~m}^{3}$ there are approximately $1 \times 10^{21}$ ions in a plasma discharge. This implies that the total high $\mathrm{Z}$ impurity level should be less than $1 \times 10^{18}$ particles or $2 \times 10^{-6}$ moles.

The DIII-D tokamak has a $35 \mathrm{~m}^{3}$ Inconel vacuum vessel designed for ultrahigh vacuum, with a base pressure of $\mathrm{P}<2.0 \times 10^{-8}$ Torr. The vacuum vessel is routinely baked up to an average temperature of $350^{\circ} \mathrm{C}$. Areas on the inner wall can go as high as $380^{\circ}$ and areas recessed in ports can be as low as $150^{\circ} \mathrm{C}$. Materials proposed for use in the DIII-D vacuum vessel must have low outgassing rates and be stable at elevated temperatures. Often materials proposed for use in the DIII-D vacuum vessel do not have published outgassing data or the outgassing data does not include behavior at elevated temperatures.

As an aid in determining whether materials were suitable for DIII-D a simple outgassing chamber was built. The initial requirements for the chamber were that it be easy to use, give reproducible results and give quantitative numbers that were correct to at least an order of magnitude. Initial tests on the pumpdown behavior of $\mathrm{MgO}$ insulated coaxial cables, graphite, and Grafoil@ will be presented. The techniques used to acquire quantitative information regarding the outgassing rate will be discussed. These included the rate-of-rise technique used to measure the outgassing rate, as well as RGA spectra taken during the pumpdown tests. Plans to modify the outgassing station based on these initial tests will be presented. 


\section{OUTGASSING STATION}

The outgassing tests were performed in a $18 \ell$ stainless steel vacuum chamber with a wall surface area of $7.4 \times 10^{3} \mathrm{~cm}^{2}$ (Fig. 1). Pumping was supplied by a $330 \ell / \mathrm{s}$ turbo-molecular pump isolatable from the chamber by a pneumatically controlled valve. The chamber was equipped with a Residual Gas Analyzer (RGA), an ion gauge, and a 3.6 $\times 10^{-6}$ Torr- $\ell / s \mathrm{~N}_{2}$ leak. Through the use of heater tapes the temperature of the entire chamber could be raised to $400^{\circ} \mathrm{C}$.

An initial series of pumpdown tests were performed on materials present in the DIII-D tokamak to develop a baseline on acceptable materials. For the initial pumpdown tests the chamber was continuously vented to $\mathrm{N}_{2}$ while the samples were being inserted. The time the chamber was opened to insert the samples was kept the same for all the samples. The outgassing rate was measured by using rate-of-rise measurements, i.e. the pumping to the vacuum chamber was shut off and the rate of rise of the pressure was determined from the slope of the ion gauge's pressure reading. The ion gauge was calibrated using the $\mathrm{N}_{2}$ calibrated leak. All pumpdown tests were performed at room temperature. Typical pumpdown data for the chamber is shown in Fig. 2. The background level of the outgassing chamber was approximately $1.8 \times 10^{-8}$ Torr- $\ell / \mathrm{s}$.

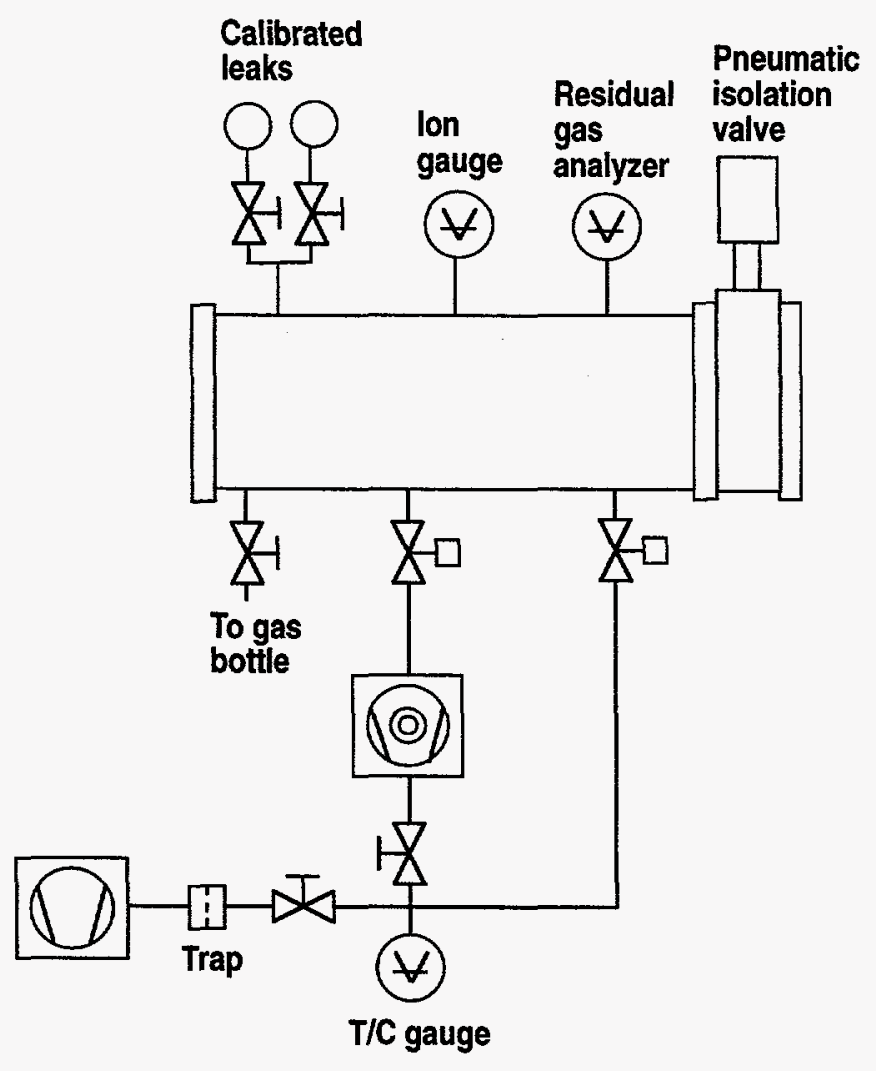

Fig. 1. Schematic of the outgassing station. 


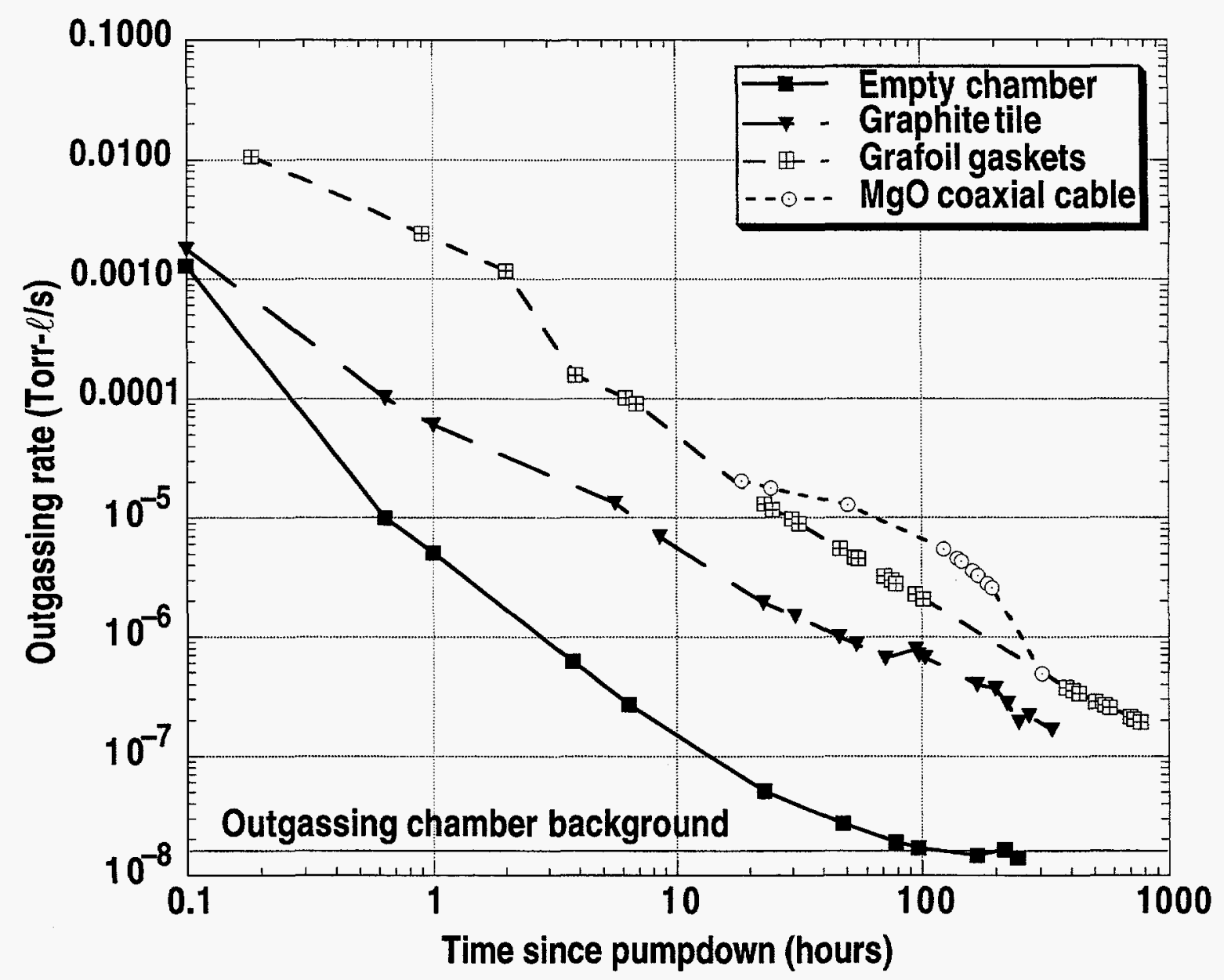

Fig. 2. Total outgassing rates during pumpdown tests for various materials used in the DIII-D tokamak. Tests were performed at room temperature. 


\section{MgO COAX}

$\mathrm{MgO}$ insulated coaxial cable is used in the DIII-D vessel to transmit electrical signals. The outer sheath is composed of stainless steel and is 0.06 inches in diameter. The inner central conductor is copper. The region between the sheath and central conductor is filled with $\mathrm{MgO}$ powder. Eighty percent of the $\mathrm{MgO}$ power has a diameter of less than $38 \mu \mathrm{m}$ and all of the powder has a diameter less than $75 \mu \mathrm{m}$. The powder is approximately $75 \%$ dense. Test material was taken from a long roll of coax which had one end open to air for approximately six months. This roll was cut into five approximately 25 foot lengths which were exposed to air for approximately 24 hours before being inserted into the outgassing chamber.

The test method for the pumpdown tests was slightly modified for the $\mathrm{MgO}$ cables. After the coax was inserted into the outgassing chamber, the station was baked to approximately $200^{\circ} \mathrm{C}$ for four hours in an attempt to lower the water levels. The chamber was then allowed to cool to room temperature before outgassing measurements were taken. The outgassing rate for these $\mathrm{MgO}$ cables decreased approximately exponentially with an e-folding time of 80 hours from an initial value of $3 \times 10^{-5}$ Torr- $\ell / \mathrm{s}$ (Fig. 2).

The exponential decay suggests that the outgassing is simply from the coax being evacuated of free gas vapor trapped in the open spaces of the $\mathrm{MgO}$ powder. The time evolution of the pressure for the evacuation of a tube with a distributed gas load can be found as [1]

$$
p=p_{o} \frac{4}{\pi} \sum_{n=0}^{\infty}(2 n+1)^{-1} \sin \frac{\pi(2 n+1) x}{2 L} \exp \left[-\frac{\pi^{2}}{4}(2 n+1)^{2} \frac{C}{V} t\right]
$$

where $C$ is the conductance of the tube, $V$ is the volume in the line, and $L$ is the length of the line. Analogous to the diffusion equation, the time dependent gas flow out of the end of the cable, $Q$, will be assumed to be of the form

$$
Q=2 f\left(\frac{\partial p}{\partial x}\right)_{x=0}
$$

where $f$ is analogous to the diffusion coefficient. The total outgassing rate can then be expressed as

$$
Q=q_{o} \sum_{n=0}^{\infty} \exp \left\{-[\pi(2 n+1)]^{2} \frac{C}{V} t\right\}
$$

where $q_{0}$ is the initial outgassing rate. 
In order to test the validity of Eq. (3), the exponential term can be calculated and compared to the experimentally determined value from the pumpdown tests (Fig. 2). In order to calculate Eq. (3) the conductance, $C$, must be determined. To accomplish this, one end of a $\mathrm{MgO}$ coax cable was terminated in the vacuum chamber and the other end in air. The throughput, $q$, through the $\mathrm{MgO}$ coax was measured using the rate-of-rise method. The $\mathrm{MgO}$ cable was then shortened and the throughput again measured generating a plot of throughput versus length. The conductance can be found from $C=q \Delta P$ where $\Delta P$ is 760 Torr (Fig. 3). For the pumpdown tests the length of the $\mathrm{MgO}$ coax was approximately $760 \mathrm{~cm}$. The conductance, $C$, used in Eq. (3) is based on half of this length or $360 \mathrm{~cm}$ since both sides are open to vacuum. Extrapolating from the results in Fig. 3 gives a value for $C$ of approximately $1.7 \times 10^{-9} \ell^{*} \mathrm{~s}^{-1}$.

With the value of $C$ determined the exponential factor in Eq. (3) can be estimated for the $\mathrm{MgO}$ coax cable used in the pumpdown tests. For 25 feet of $\mathrm{MgO}$ coax cable the volume of free space, $V$, can be estimated as $3.2 \times 10^{-3} \ell$. Keeping only the $n=0$ term in Eq. (3) yields the result $q=q_{0} \exp \left[-5.3 \times 10^{-6} t\right]$. The exponential factor is only 1.5 times greater than the value of $3.5 \times 10^{-6} \mathrm{~s}^{-1}\left(1 / 80\right.$ hours $\left.^{-1}\right)$ obtained empirically from the pumpdown test. This implies that the bulk of the measured outgassing rate is from free gas vapor in the $\mathrm{MgO}$ cable and not to intrinsic impurities which might be deleterious to plasma operations.

The total amount of gas released from the five cables, found by integrating under the curve in Fig. 2, was 8.5 Torr $\ell$. There is an estimated 13.8 Torr- $\ell$ of free gas in the coax which is only 1.6 times greater than what actually outgassed. Again this implies the bulk of the outgassing is simply due to air diffusing out of the $\mathrm{MgO}$ coax.

The termination of the ends of the $\mathrm{MgO}$ coax is accomplished in two different ways on the DIII-D vessel. In some applications one end of the $\mathrm{MgO}$ coax terminates outside of the DIII-D vessel with the $\mathrm{MgO}$ powder exposed to air and the other end terminates inside the vessel with a vacuum tight seal. If the seal breaks there would be a leak into the DIII-D vessel through the coax. On DIII-D vessel the maximum outgassing/leak rate for a single diagnostic is $3 \times 10^{-7}$ Torr- $\ell / \mathrm{s}$. Extrapolating from the data in Fig. 3 the coax would have to be longer than $15 \mathrm{~m}$ long in order that the air throughput not exceed this maximum outgassing/leak rate. Since most cables are shorter than $15 \mathrm{~m}$ any coax that penetrates the DIII-D vessel must be terminated in a secondary vacuum chamber.

The second method for terminating MgO coax is to terminate both ends inside the DIII-D vessel with vacuum tight seals. This creates a trapped volume with the possibility of a virtual leak occurring if a crack develops in the coax or the seal. However, the amount of trapped gas in the $\mathrm{MgO}$ coax is fairly small. Assuming that the coax is initially at 760 Torr there are approximately 0.3 Torr- $\ell$ of gas in one meter of the coax. For comparison, the typical air leak rate on DIII-D is approximately $3 \times 10^{-5}$ Torr- $\ell / \mathrm{s}$ which corresponds to 2.6 Torr- $\ell$ of air per day. 
Thus the total amount of gas in a $9 \mathrm{~m}$ length of coax is equivalent to what leaks into the DIII-D vessel during one day.

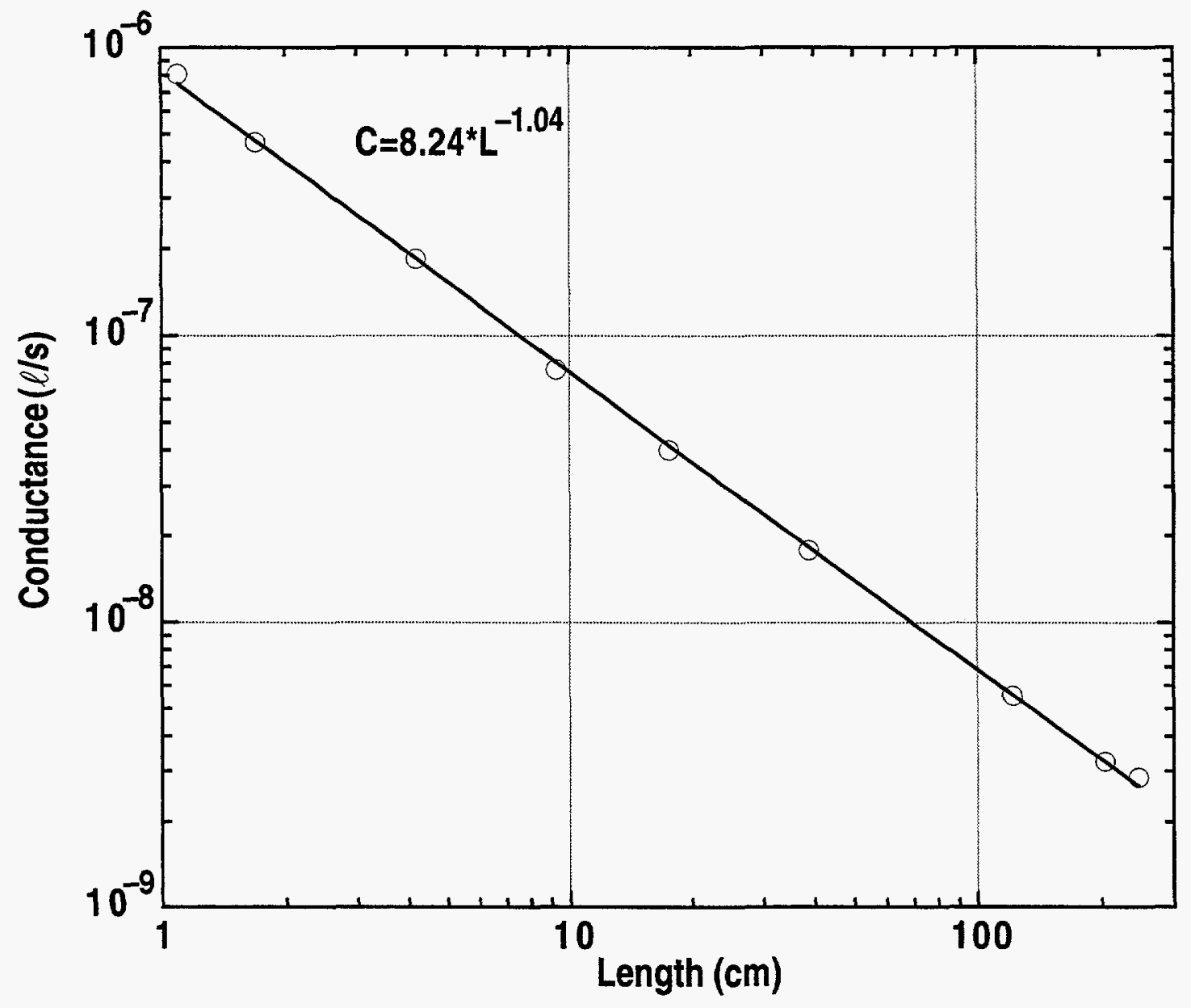

Fig. 3. The conductance for various lengths of $\mathrm{MgO}$ insulate coaxial cables. 


\section{GRAPHITE TILE}

All plasma facing surfaces (except for port openings) are armored with graphite tiles (Union Carbide ATJ). There are approximately 3,000 tiles in the DIII-D vessel. A single representative tile was tested in the outgassing chamber. The tile had a volume of approximately $462 \mathrm{~cm}^{3}$ and a geometric surface area of $617 \mathrm{~cm}^{2}$. The outgassing rate per geometric surface area as a function of time is shown in Fig. 4. There is a rapid decrease in the outgassing rate during the first hour fittable by the power law relationship, $Q=9.1 \times 10^{-8} t^{-1.5}$ (Torr- $\ell / \mathrm{s} / \mathrm{cm}^{2}$ ) and then the outgassing rate follows the power law relationship, $Q=8.8 \times 10^{-8} t^{-1}$. The total amount of gas outgassed after one hour, extrapolating to the background level of the outgassing chamber, corresponds to 200 monolayers of gas based on the geometric surface area.

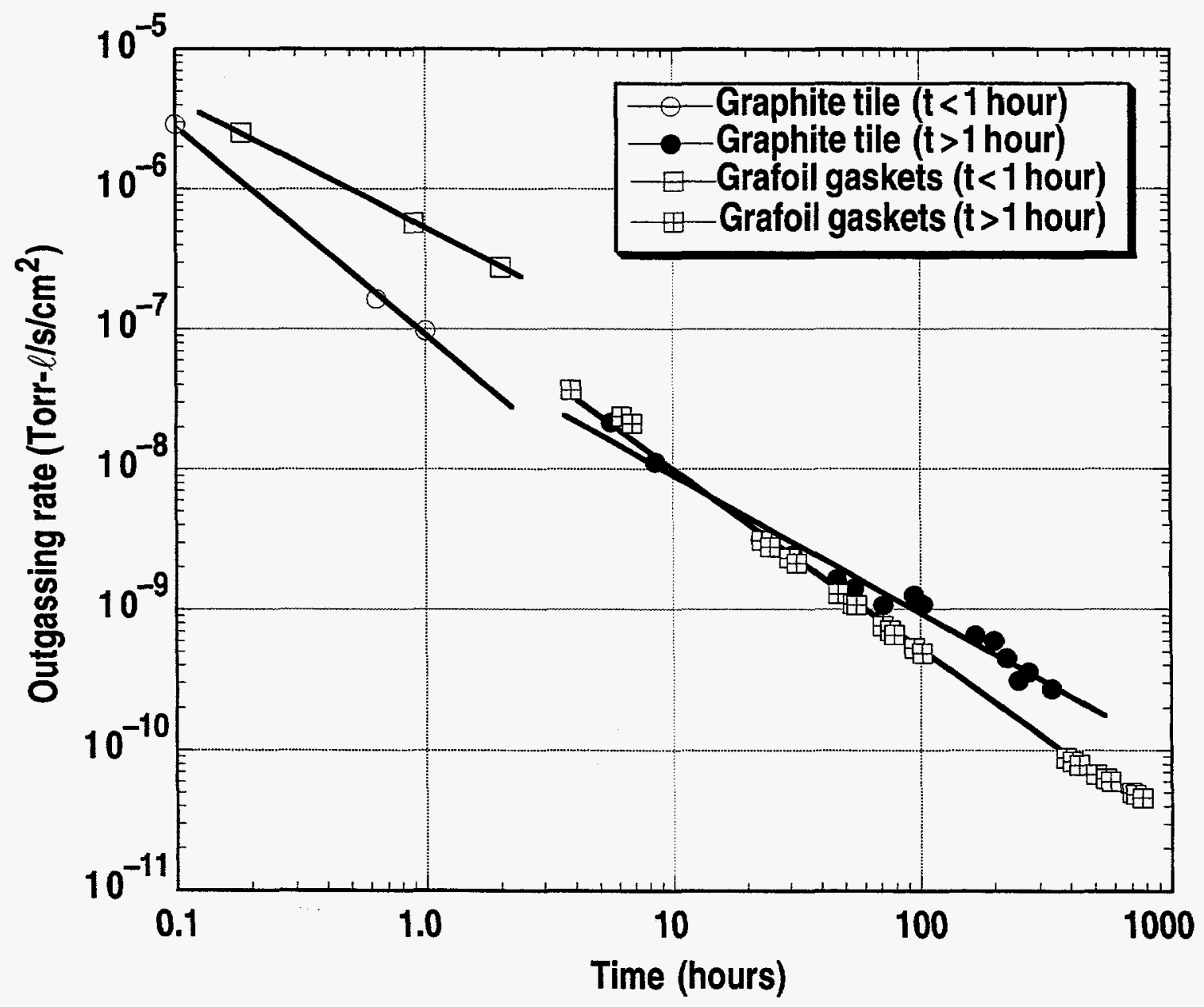

Fig. 4. Outgassing rates per unit area for the graphite tile and for the Grafoil@ gaskets. Tests were at room temperature. 


\section{GRAFOIL@ GASKETS}

Grafoil@ gaskets (a porous compressible form of graphite) are installed between the graphite tiles and the Inconel wall in the DIII-D tokamak. These gaskets increase the thermal conductivity to the wall while decreasing the stress concentrations in the tiles. There are approximately 13,000 Grafoil@ gaskets in the DIII-D vessel. Thirty-one 80 mil thick Grafoil@ gaskets (Union Carbide GTA and GHL-A nuclear grade Grafoil®) were placed in the outgassing station. The dimension of these gaskets were $10 \mathrm{~cm} \times 6.5 \mathrm{~cm} \times 0.22 \mathrm{~cm}$ which gives a total geometric surface area of $4250 \mathrm{~cm}^{2}$ and a total volume of $443 \mathrm{~cm}^{3}$.

The outgassing rate as a function of time is shown in Fig. 4. As with the graphite tiles the outgassing rate is best fit by splitting the pumpdown into two separate sections. For the first hour the outgassing follows the power law relationship, $Q=5.3 \times 10^{-7} t^{-0.9}$ after which the outgassing follows the power law relationship $Q=1.9 \times 10^{-7} t^{1.3}$. Unlike the graphite tile, the gasket outgassing coefficient increases after the first hour.

The total amount of gas released starting at one hour and extrapolating to the background level of the outgassing station is 16.8 Torr- $\ell$. As with the graphite tile the total amount of gas outgassed after one hour would correspond to 200 monolayers of gas based on the geometric surface area. It is unexpected that the outgassing behavior of the graphite tile and the Grafoil@ gaskets are so similar since Grafoilß is very porous. However, if the pore size in the Grafoilß is large enough the bulk of the air may be evacuated quickly. During the first hour the outgassing rate is considerably higher for Grafoil $@$ than for graphite. In addition, the pumpdown tests were performed at room temperature and it is expected that at elevated temperatures the Grafoilß would have a higher outgassing rate than the graphite. 


\section{DISCUSSION OF RATE-OF-RISE MEASUREMENTS AND RGA SCANS}

To determine the outgassing rate the rate-of-rise method was used with the pressure being measured by a hot filament ion gauge. This method was principally chosen due the ease of its implementation. The rate-of-rise measurements were calibrated versus a $3.6 \times 10^{-6}$ Torr- $\ell / \mathrm{s} \mathrm{N}_{2}$ leak. The incremental rise in the outgassing rate always agreed very well with the calibrated leak value indicating that the determined outgassing rate, for $\mathrm{N}_{2}$ at least, was correct. If it could be verified that the ratios of the partial pressures of all the main gas species remained the same during the rate-of-rise measurements then the measurement could be considered to be giving a valid indication of the true outgassing rate. A rough quantification of the partial pressure ratios was made by comparing the RGA values for the initial concentration prior to the start of a rateof-rise measurement with the outgassing rates measured for the gases during the measurement (Fig. 5, Table 1). All the RGA values were normalized to mass 28 . The outgassing rate was determined using a linear fit and ignoring the first few non-linear points. The final column in Table 1 shows the ratio of the initial gas species concentration with their rate of rise.

The scan taken just prior to the rate-of-rise measurement shows that the dominant gas species is $\mathrm{H}_{2} \mathrm{O}$ (mass 18). However, as can be seen from the final column in Table 1 for $\mathrm{H}_{2} \mathrm{O}$, $\mathrm{Ar}$ (mass 40 ), and most noticeably $\mathrm{O}_{2}$ (mass 32 ) the outgassing rate is much lower than would be expected from the initial concentration levels. This value should be close to unity if the outgassing rate is proportional to the initial concentration.

There are a number of explanations for this results, none of which is completely satisfactory. If readsorption was responsible it would be expected that the rate of rise would increase with time [2] while in actuality following a rapid increase the pressure rate of rise decreases and then follows a constant rate. Another possibility is that the effective pumping speed of these gases is very low. It has been observed that it is difficult to pump water due to its ability to absorb on surfaces [3]. A similar effect could be true of $\mathrm{O}_{2}$ but seems unlikely for Ar. The foreline to the turbo pump could have higher than expected levels of air. However, the compression for Ar is high enough that this shouldn't be a major factor. A final explanation may be that since the pressure during the rate-of-rise measurement increases into the $10^{-3}$ range by the end of the measurement, the RGA's response becomes non-linear [4,5]. This explanation could account for the behavior of $\mathrm{Ar}$ but not for $\mathrm{H}_{2} \mathrm{O}$ or $\mathrm{O}_{2}$.

The above behavior is of particular interest because there is interest in using the throughput method for determining the outgassing rate. The scan just prior to the start of the rate-of-rise measurement can be considered as representative of a throughput measurement (although 
through a very large conductance). However, on the basis of the above discussion it would be difficult to interpret RGA spectra using this method. Calibrated leaks can be obtained for many of the gases present and used to characterize their behavior. Water, however, poses greater difficulty. While methods have been studied for determining water outgassing $[3,6]$ it needs to be determined whether they can be incorporated into our outgassing chamber. Similarly, the accurate quantification of volatile gases released during measurements at elevated measurements appears difficult using only the RGA and ion gauges.

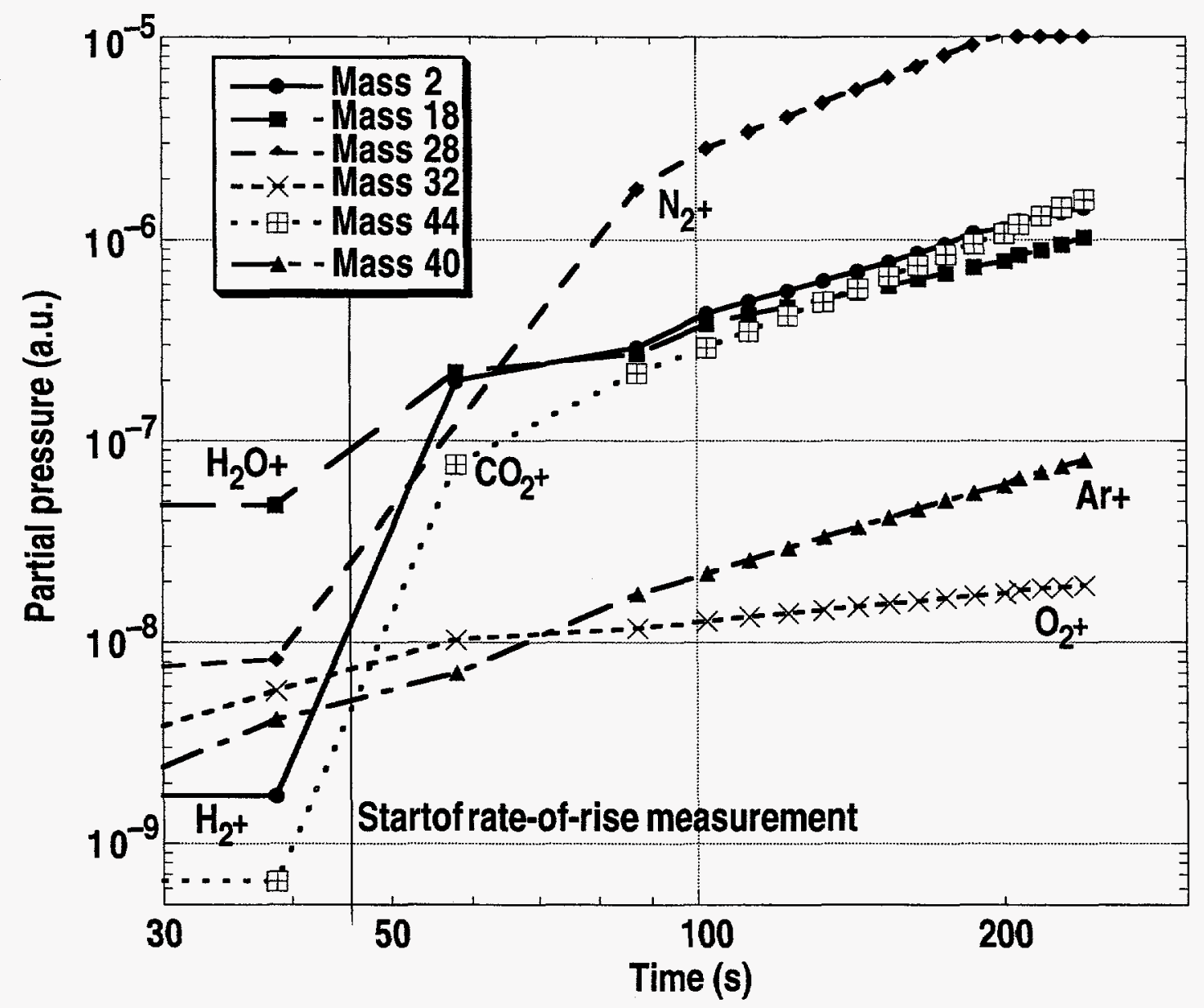

Fig. 5. Time evolution of partials peaks during a rate-of-rise measurement for Grafoil $($ The test was at room temperature. 
Table 1

The Partial Pressure Just Prior to a Rate-of-Rise Measurement and the Calculated Outgassing Rate From the Rate-of-Rise Measurement.

\begin{tabular}{|c|c|c|c|}
\hline $\begin{array}{c}\text { Gas } \\
\text { species }\end{array}$ & $\begin{array}{c}\text { Initial concentration } \\
\text { (normalized to mass 28) }\end{array}$ & $\begin{array}{c}\text { Outgassing rate } \\
\text { (normalized to mass 28) }\end{array}$ & $\begin{array}{c}\text { Initial concentration/ } \\
\text { outgassing rate }\end{array}$ \\
\hline \hline 2 & 0.3 & 0.1 & 2.6 \\
\hline 18 & 7.5 & 0.06 & 125 \\
\hline 28 & 1 & 1 & 1 \\
\hline 32 & 0.3 & $7 \times 10^{-4}$ & 415 \\
\hline 40 & 0.04 & $5 e-3$ & 25 \\
\hline 44 & 0.1 & 0.1 & 1 \\
\hline
\end{tabular}




\section{HIGH TEMPERATURE TESTS}

Another of the primary purposes of the outgassing chamber was to determine whether volatile substances were released at elevated temperatures. Preliminary tests on the above three materials showed nothing unexpected, with the RGA spectra being dominated by water. However, the tests indicated that heating the entire chamber in order to heat the sample has several disadvantages; these include high background levels, shortened vacuum seal life, and various safety issues. 


\section{MODIFICATIONS TO THE OUTGASSING STATION}

Based on the initial tests the outgassing station is being modified (Fig. 6). A ceramic heating system capable of attaining temperatures up to $700^{\circ} \mathrm{C}$ is being added to heat the samples. To monitor the sample temperatures a linear feedthrough with a thermocouple on the end can be inserted until it contacts the sample. The temperature of the chamber walls will be independently controllable. This will allow the walls to run at slightly elevated temperatures, e.g. $50^{\circ}-100^{\circ} \mathrm{C}$, to reduce the sticking probability of volatile gas species.

Despite limiting the amount of time the chamber was open and continuously purging with $\mathrm{N}_{2}$, the chamber still absorbed large amounts of water. To help alleviate this problem a load-lock chamber has been built. After the load-lock chamber has been evacuated samples loaded onto a stainless steel tray can be inserted into (or retracted from) the main outgassing station along guide rails with the use of a linear feedthrough.

The throughput method of using the pressure drop across known orifices is being added although as mentioned earlier there are concerns regarding calibration. The problem of deriving quantitative numbers from the outgassing measurements is still being investigated. Further calibrated leaks can be installed to better characterize the expected effect of specific gases on the ion gauge, the RGA spectrum and the effective pumping speeds. However, there is a narrow range of gases available in commercially available leaks. It is unlikely that volatile gases, which could be evolved during tests at elevated temperatures, can be obtained. As discussed earlier, methods to quantify water have not yet been determined. 


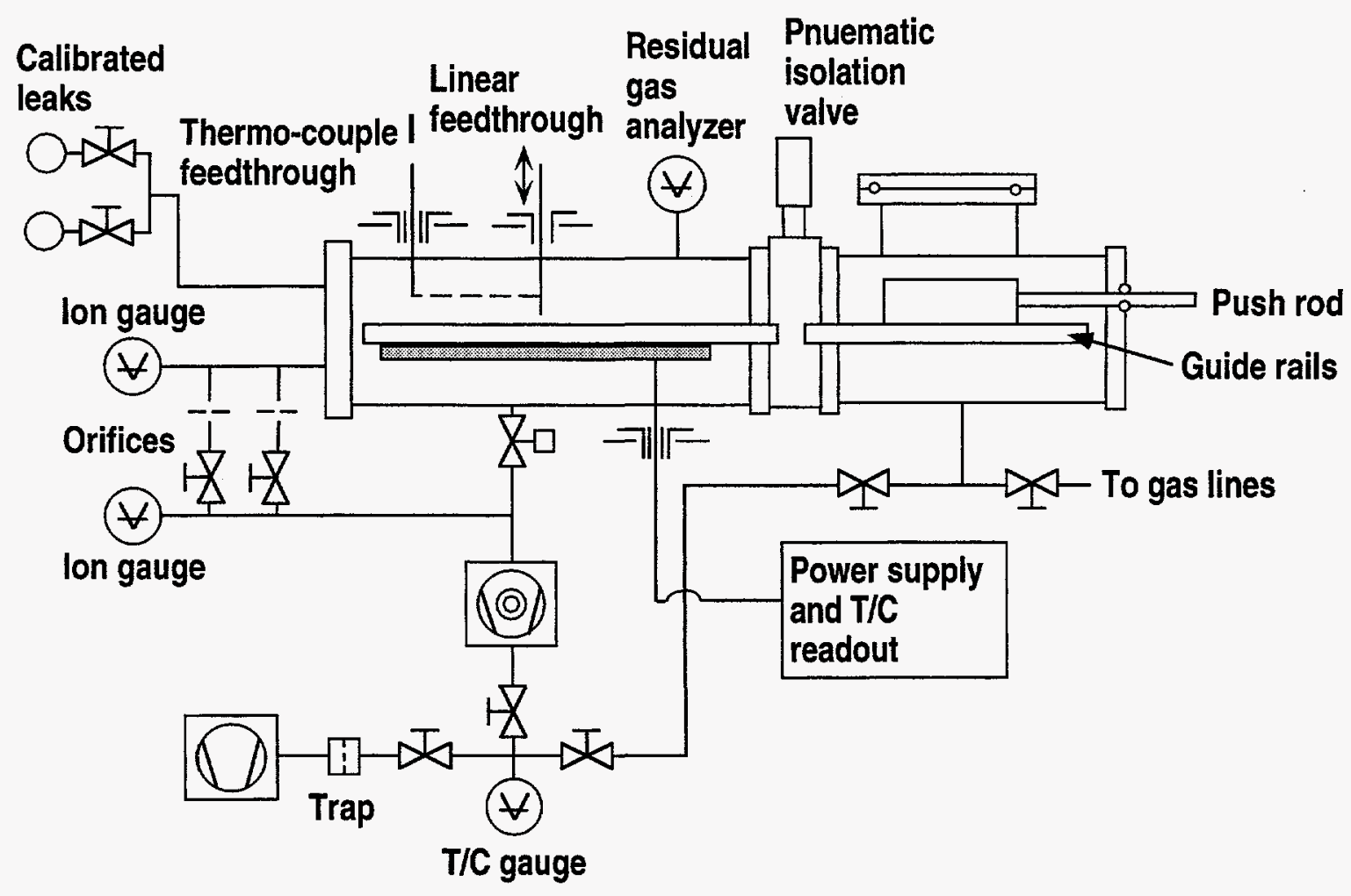

Fig. 6. Schematic of the modified outgassing station. 


\section{CONCLUSIONS}

Pumpdown tests were performed on graphite, Grafoil@, and $\mathrm{MgO}$ insulated coaxial cable. Based on these results it was possible to accurately determine the removal of $\mathrm{N}_{2}$ using the rateof-rise method to determine the outgassing rate. However, RGA scans taken during the pumpdown tests did not correlate with rate-of-rise measurements; the behavior of water was especially anomalous. From experience based on these tests several modifications were made to the outgassing chamber to increase the flexibility and sensitivity of the system. These include a load-lock chamber to reduce air contamination, and a ceramic sample heater. 


\section{REFERENCES}

[1] G. Lewin, 1965, Fundamentals of Vacuum Science and Technology (McGraw-Hill, New York)

[2] P.A. Redhead, J. Vac. Sci. Technol. A Vol. 14 (1996).

[3] J.A. Basford, J. Vac. Sci. Technol. A Vol. 12 (1994).

[4] J. Vac. Sci. Technol. A 8 (1990).

[5] Vacuum, Vol. 37 335-338 (1990).

[6] M. Li, H.F. Dylla, J. Vac. Sci. Technol. A Vol. 11 (1993). 


\section{ACKNOWLEDGMENT}

Work supported by U.S. Department of Energy under Contract No. DE-AC03-89ER51114. 